\title{
Prevalence of malocclusion among school Children of Kathmandu, Nepal
}

\author{
Dr Manju Bajracharya,' Dr Sunanda Sundas, ${ }^{2}$ Dr Resina Pradhan, ${ }^{3}$ Dr Surendra Maharjan4 \\ 1.3.4Assistant Professor, ${ }^{2}$ Associate professor, People's Dental College and Hospital, Nepal
}

Correspondence: Dr Manju Bajracharya; Email: manjub7g@hotmail.com

\section{ABSTRACT}

Introduction: this study was carried to understand Prevalence of malocclusion among the school children of Kathmandu, Sorakhutte residing near school during mixed dentition period. A sample of 600 children; 365 male, 235 female in age group of 6-13yrs was selected randomly from different school of Kathmandu city. The aim of our study is to find out prevalence of malocclusion among the mixed detention children of Kathmandu.

Materials \& Method: Data was collected using direct observation of the subjects, Descriptive cross-sectional study method was used in this research. Occlusal assessment were done according to angle's classification and dewey's modification type of class I, class III malocclusion.

Result: Subjects with normal occlusion was found to be $59.3 \%$ and with malocclusion was found to $40.7 \%$. Among them class I malocclusion was majority of (57\%) of study population, crowded incisors and significant difference was observed between male and female in the study.

Conclusion: This study helps to access the prevalence malocclusion and need of orthodontic treatment for the mixed dentition period children.

Keywords: Malocclusion, Nepal, prevalence

\section{INTRODUCTION}

Malocclusion is one of oral health problems that affects individual socially, and psychologically. According to Edward Angle "A malocclusion may be defined as any deviation from normal occlusion of teeth while normal occlusion is the normal relation of occlusion inclined planes of the teeth when the jaws are closed". ${ }^{16}$ There is very less information about the malocclusion in the community. A well organized and systematic program is require to spread knowledge about this problem in the community.

In most of the developed countries where faculty of orthodontics and pedriatic dentistry are well established have provided information about prevalence of malocclusion and its treatment need to community to great extent. But country like Nepal which is still in the developing state is lacking behind in creating awareness about the prevalence of malocclusion and its treatment need for developing children is necessary. The malocclusion if not figured out in the initial stage then in later stages it will be complicated. So, if the malocclusion problem can be detected early, it will be easier for orthodontics to provide preventive procedure to child that will help in minimizing potential irregularity of dentofacial abnormalities.

Therefore, the aim of this study is to determine the prevalence of malocclusion during mixed dentition period among the school children of Kathmandu valley.

\section{MATERIAL AND METHODS}

Descriptive cross sectional study was conducted to assess the prevalence of malocclusion among school children of 6-13 years from 10 different school of Kathmandu valley. Six hundred students (male (365) and female(235)) from different school of Kathmandu between age group 6 years and 13 years were selected randomly for the study. Those considered 600 children visited the pedriatics department of people's dental college and hospital, Sorrhakhutte Kathmandu. All those children have never done orthodontic treatment before, they all have presence of incisors and first permanent molars were included for study; children with all permanent dentition and those children who has started early orthodontic treatment were excluded. 
This study has been conducted after taking consent from parents of all the children and their schools. Ethical clearance from Institutional Review Board (IRB), Institute of Medicine (IOM) has been taken to conduct this study. The students are examined by diagnostic instrument with disposable gloves and mouth mask with halogen light chair of electronic dental chair. All the subjects were asked to bite on her or his teeth in centric occlusion. The occlusion was examined whether it is normal or malocclusion according to angle's classification with dewey's modification type. Children with proper class I molar relation of minimal overjet, overbite, crowding, spacing etc is considered as normal occlusion. In subjects with class I malocclusion dewey's modification type I is consider as crowded incisors, canines or both, type II is protruded maxillary incisors, type III is anterior crossbite, type IV is unilateral and bilateral posterior crossbite, type $V$ is mesial drift of molars, anterior or posterior openbite, deep overbite. All data were analyzed and tabulated statistically using SPSS 20 software.

In subjects with class III malocclusion dewey's modification type I is normal incisor overlapping, type II is edge to edge incisor relationship, type III is incisors are in crossbite.

\section{RESULT}

A statistical analysis was performed with the collected data. Result of the analysis is shown in tables and figures.

Table 1 shows that there are 244 children with malocclusion and 356 children without malocclusion. Among those 244 children, 167 (45.8\%) male has malocclusion and 77 (32.8\%) female have malocclusion, malocclusion in male is greater than in female.

Out of 600 subjects, 356 (59.3\%) subjects were without malocclusion, here, more female subjects (67.2\%) are found than male (54.2\%).

Class I malocclusion (67\%) in significantly greater compared to class II (20\%) and class III malocclusion(13\%) which is shown in figure 1. Among dewey's modification type class I type 1 malocclusion(32\%) is more than type $2(12 \%)$, type $3(29 \%)$, type $4(8.5 \%)$, type $5(4 \%)$, also angles class I bimaxillary protrusion is $3 \%$, open bite is $8 \%$ seen in figure 2. Again, in figure 3,Angle's class II div I malocclusion is (90\%) more than div 2(10\%) malocclusion. Also, class III malocclusion with dewey's modification type, class III type $3(38 \%)$ is more than type $1(27 \%)$, type 2 (16\%), subdivision $16 \%$.

Table1: Distribution of children with and without Malocclusion Cases

\begin{tabular}{|c|c|c|c|}
\hline \multirow{2}{*}{ Sex } & \multicolumn{2}{|c|}{ Number of patients } & \multirow{2}{*}{ Total patients } \\
\cline { 2 - 3 } & With Malocclusion & Without Malocclusion & $365(60.8 \%)$ \\
\hline Male & $167(45.8 \%)$ & $198(54.2 \%)$ & $235(39.20 \%)$ \\
\hline Female & $77(32.8 \%)$ & $158(67.2 \%)$ & $600(100 \%)$ \\
\hline Total & $244(40.7 \%)$ & $356(59.3 \%)$ & 6 \\
\hline
\end{tabular}

(This indicates that malocclusion cases are significantly higher among male (45.8\%) than that of female(32.8\%).

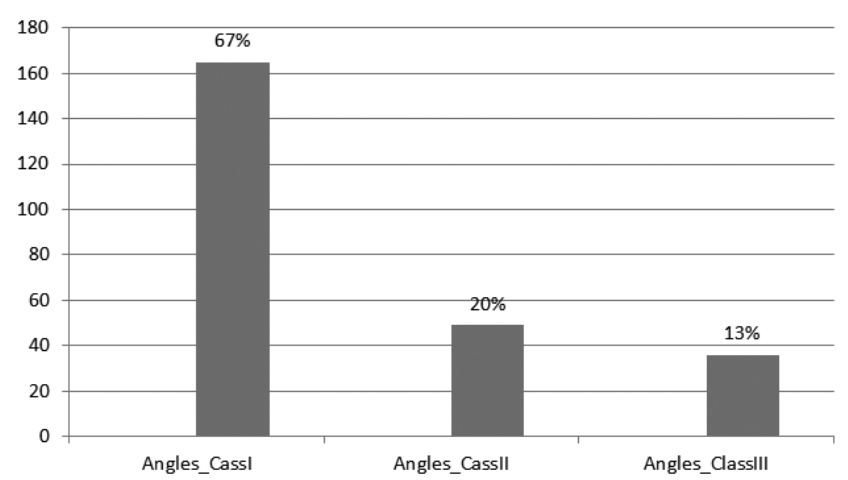

Figure1: Distribution of Malocclusion Cases

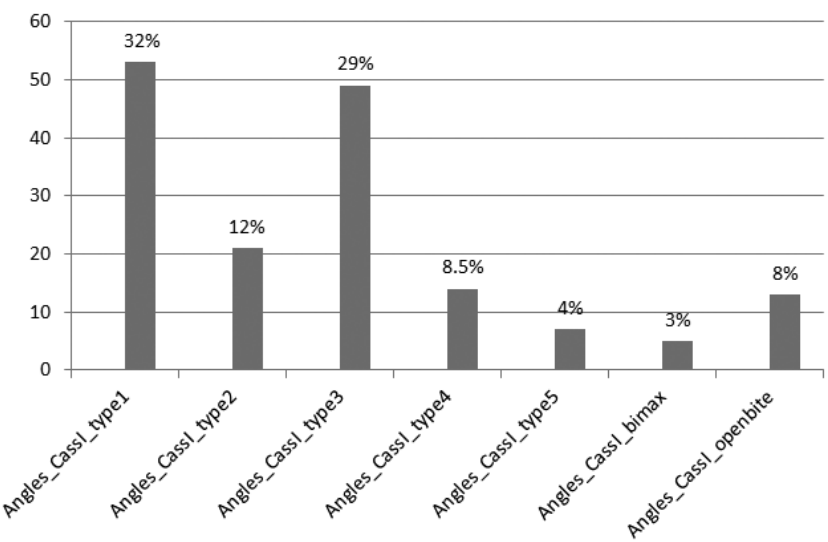

Figure2: Distribution of Malocclusion Cases of class 1 by its type 


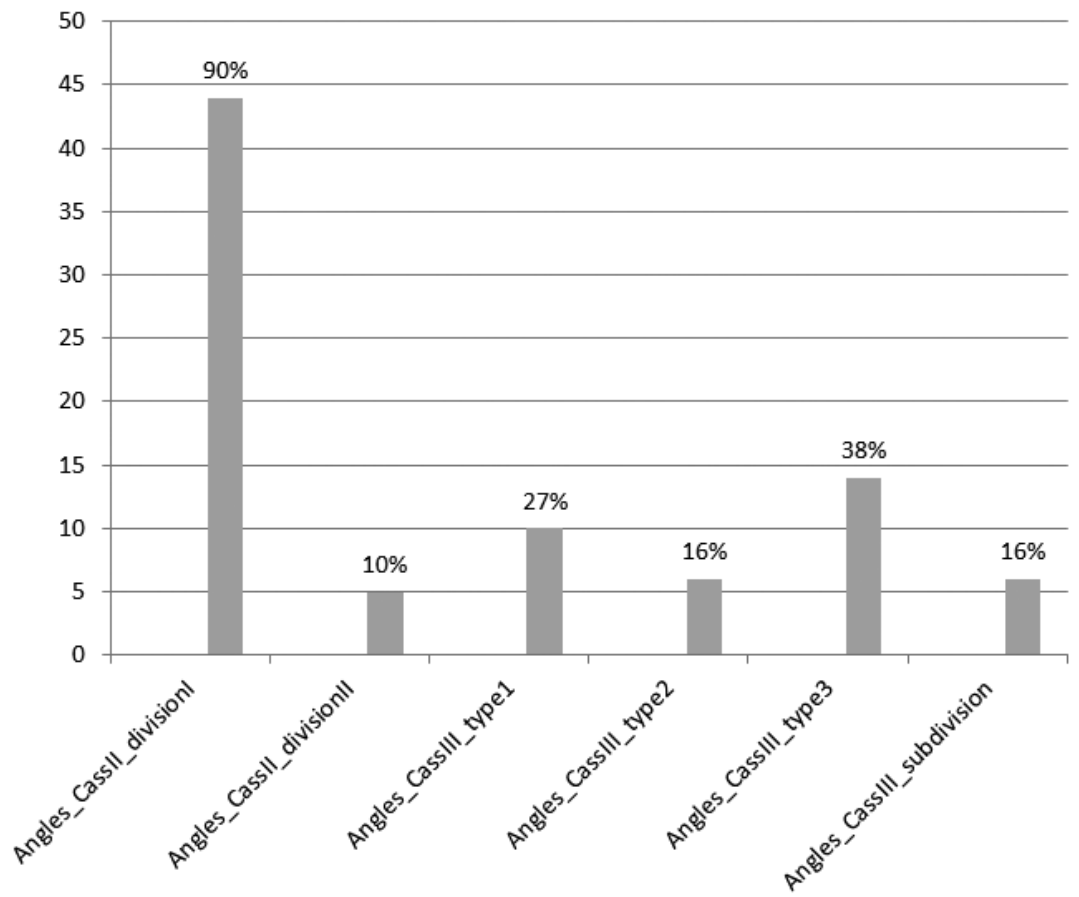

Figure 3: Distribution of Malocclusion Cases of class II and class III by its type

\section{DISCUSSION}

The study showed 244 (40.7\%) subjects have malocclusion which is nearly similar to kharbandha et $\mathrm{al}^{11}$ who found $36.6 \%$ of malocclusion in new delhi and sarbajeet singh sadhu etal 4 where malocclusion prevalence in south india is $49.2 \%$ in age group of 12 $15 y$ rs. This study disagrees with Das et al ${ }^{12}$ who conducted an epidemiologic study of malocclusion in 8-12yrs of age in bangalore city 2008, reported high incidence of malocclusion of $71 \%$, also with usha mohan das etal 2 whose result showed $71 \%$ had malocclusion incidence and dr.basanta $\mathrm{k}$ shrestha et $\mathrm{al}^{5}$ showed result of 90.4\% had malocclusion among medical students of institute of medicine in Kathmandu,Nepal. Among total subjects, 356(59.3\%) have no malocclusion while 244 (40.7\%) have malocclusion which is contrast to the study done by shiva kumar etal 14in 2009 where $80.1 \%$ have minor or no malocclusion, only $19.9 \%$ had malocclusion and need definite orthodontic treatment. Among various malocclusion type, class I (67\%) has higher range than class $11(20 \%)$ and class III (30\%) malocclusion which is similar to findings of Sharma. $\mathrm{J}^{13}$ in 2010, Umesh parajuli et $\mathrm{al}^{15}$ and also with Mridula Trehan et al. ${ }^{10}$ Mridula Trehan's study conducted in Jaipur showed prevalence of class I malocclusion
(59.9\%) is more that class II $\operatorname{div} 1 \quad(1.1 \%)$ and class III (1.4\%). This study showed male (45.8\%) predominantly higher than female (32.8\%) subject which is contrast to Mridula trehan et al, ${ }^{10}$ Usha mohan das. ${ }^{2}$

\section{CONCLUSION}

Among all Angle's classification of malocclusion, class I with dewey's modification type 1 is more prevalent compare to class II and class III malocclusion and its subdivision type. There is statistical significant greater incidence of malocclusion in male compared to female subjects in our study. So, there should be awareness programs for the prevalence of malocclusion in Kathmandu such that appropriate early needful orthodontic treatment can be provided for the developing children.

\section{ACKNOWLEDGEMENT}

I thank the faculty of deparment of Pedriatic dentistry in people's dental college and hospital, sorhakhutte, $\mathrm{ktm}$ for kindly grant me permission to conduct this study. 


\section{REFERENCES}

1. Angle EH. Classification of malocclusion. Dental Cosmos, 1899;41, 248-264.

2. Pravakar RR, Saravanan R, Karthikeyan MK, Vishunucharndran C, Sudeepthi. Prevalence of malocclusion and need for early orthodontic treatment in children. Journal of clinical and diagnostic research.2014;8(1):10-2.

3. DAS UM, Venkatsubramanian, Reddy D. Prevalence of malocclusion among school children in Banglore, India. International journal of clinical paedriatric. 2008;1(1):10-2.

4. M Trehan, VK Chugh, S Sharma - International journal of clinical pediatric dentistry. Prevalence of malocclusion in jaipur,India. International journal of clinical pedriatic dentistry. 2009;2(1):23-5.

5. Kharbandha OP, Sidhu SS, Sundaram KR, Shukla DK. Malocclusion and associated factor among Delhi children. Project report Indian council of medical research, New delhi. 1991;1 (1):10-2.

6. Sandhu SS, Bansal N, Sandhu N. Incidence of malocclusion in India. A review JOral Health Comm Dent. 2012;1 (6):21-4

7. Das UM, Venkatsubramanian, Reddy D. Prevalence of malocclusion among school children in Banglore,India. Int $\mathrm{J}$ clin Ped dent. 2008;1(1):10-2.

8. Shrestha B, Yadav R, Gyawali R, Gupta S. Prevalence of Malocclusion Among Medical Students in Institute of Medicine Nepal: A Preliminary Report. Orthodontic Journal of Nepal. 2013;1 (1): 24-27.

9. Shivakumar KM, Chandu GN, Subba RVV, Shafiulla MD. Prevalence of malocclusion and orthodontic treatment among middle and high school children of devangere city, India by using Dental aesthetic index. J Indian soc pedod prev Dent. 2009;27(4):21 1-8.

10. Sharma JN. Patterns of distribution of malocclusion in patient seeking orthodontic treatment BPKIHS from sunsari district of nepal. Health renassiance. 2010;8(2):93-6.

11. Parajuli U, Tuladhar SL, Bajracharya M, Pandey M. Prevalence of malocclusion and evaluation of orthodontic treatment need among patient in Pokhara, Nepal. Orthodontic journal of Nepal. 2018;8(1):7-10.

12. Mohamad AM, Ariffin WFM, Rosly TI, Mahyuddin A. The feasibility of index of orthodontic treatment need(IOTN) in labial segment malocclusion among 8-10 yrs old. Arch orofac sci. 2014;9(2):76-84.

13. Singh SP, Kumar V, Narboo P. Prevalence of Malocclusion among school children and Adolescents in various school region. Journal of orthodontics and Endodontics. 2015;1 (2):15.

14. Bilgic F, Gelgor IE, Celebi AA. Malocclusion Prevalence and orthodontic treatment need in central Anatolian adolescents comapred to European and other nations adolescents. Dental press J orthod. 2015;20(6):75-81

15. Bittencourt MAV, Machado AW. An overview of prevalence of malocclusion in 6-10 yrs of children in Brazil. Dental press $\mathrm{J}$ orthod. 2010;12(11):113-22. 